\title{
Time-resolved 3D characterisation of early-age microstructural development of Portland cement
}

\author{
James E. Vigor ${ }^{1,2}$, Susan A. Bernal ${ }^{1,2, \star}$, Xianghui Xiao ${ }^{3,4}$, and John L. Provis ${ }^{2, *}$ (1) \\ ${ }^{1}$ School of Civil Engineering, University of Leeds, Woodhouse Lane, Leeds LS2 9JT, UK \\ ${ }^{2}$ Department of Materials Science and Engineering, The University of Sheffield, Sheffield S1 3JD, UK \\ ${ }^{3}$ Argonne National Laboratory, 9700 S Cass Avenue, Lemont, IL 60439, USA \\ ${ }^{4}$ Office 365 Brookhaven National Laboratory, PO Box 5000, Upton, NY 11973-5000, USA
}

Received: 26 November 2021

Accepted: 22 January 2022

Published online:

10 February 2022

(C) The Author(s) 2022

\begin{abstract}
Time-resolved in-situ synchrotron X-ray microtomography reveals new levels of detail about the chemical and physical processes that take place as Portland cement hardens. The conversion of a fluid paste into a hardened product can be monitored on a sub-minute time-scale, and with sample movement/settlement corrections applied to enable individual particles to be tracked as they react, hydrate, and become interconnected into a single strong monolith. The growth of the strength-giving hydrate phases surrounding cement grains, and of the fluid-filled pore network that surrounds them, is able to be directly viewed at the level of individual cement particles through the application of this tracking protocol. When cement is brought into contact with water, a layer which differs in density from the bulk of the cement grains becomes observable on the grain surfaces during the induction period (during which time the heat evolution from the paste is relatively low). As hydration continues, reaction products grow both from particle surfaces into the initially fluid-filled region, and also into the space originally occupied by the cement particles, forming a density gradient within the microstructure. As the reaction accelerates and larger volumes of solid phases precipitate, the newly-formed solid structure percolates via interconnection of agglomerated low-density outer hydrates, which then densify as hydration continues. This eventually leads to solidification of the structure into a hardened porous matrix.
\end{abstract}

Handling Editor: M. Grant Norton.

Address correspondence to E-mail: s.a.bernallopez@leeds.ac.uk; j.provis@sheffield.ac.uk 


\section{GRAPHICAL ABSTRACT}

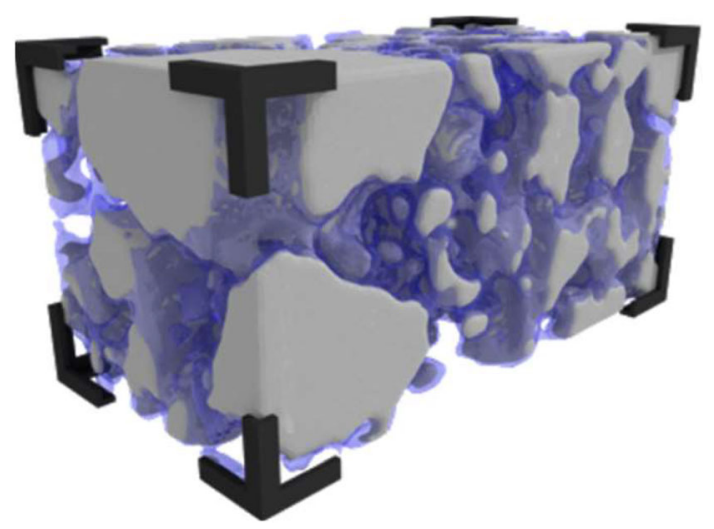

\section{Introduction}

Portland cement is the most widely used manufactured material on Earth, being produced in quantities of approximately $4 \mathrm{Gt}$ p.a. and is ubiquitous in use in modern society. Cement, in some form, is used in almost every structure in the modern world. However, despite this, important unanswered questions remain regarding the chemistry of the complex reaction process that underpins the setting and hardening of cement [1].

The strength and durability of concretes whose main binding component is Portland cement are controlled by the microstructure of the hardened cement paste, including a strong influence from the nanometre- to micron-scale porosity present within the hardened cementitious matrix [2]. This porosity results from the inability of hydrate phases to entirely fill the space within the hardened material, which is governed by the mechanism by which they form and grow to fill the initially fluid-filled spaces as cement paste hydrates [3]. The development of a fuller understanding of the early-age development of these characteristics is therefore critical in producing materials which are durable, sustainable, and offer excellent mechanical properties at early age and also throughout their service life.

The solidification process of Portland cement occurs due to a complex sequence of chemical reactions, involving and mediated by water, as the initially present anhydrous clinker minerals are converted to an assemblage of strength-giving hydrates [4]. However, due to the challenges associated with conducting in-situ analysis of solid-fluid reactions involving up to 10 different mineral phases, taking place at a $\mathrm{pH}$ of up to 13.5 , it has not yet been possible to fully characterise the first minutes to hours of this process across all the length scales-from angstroms to millimetres-which influence the setting and hardening of the cement.

Using the high-flux X-ray sources and advanced detectors available at synchrotron facilities, it is now possible to acquire high-resolution crystallographic $[5,6]$ and microtomographic $[7,8]$ data with an unprecedented time resolution. Although synchrotron X-ray diffraction techniques have previously enabled the materials science of cements to be observed and quantified [8-10], complete data regarding changes in the morphology and structure of these materials on short time scales have remained elusive despite recent advances [11-13]. Scanning times of $12 \mathrm{~min}$ have been achieved using laboratory instruments [13], while much shorter scan times (e.g. a $5 \mathrm{~s}$ scan taken every $10 \mathrm{~min}$ [12]) have been demonstrated using synchrotron sources. However, no data have been reported for hydration times of less than $30 \mathrm{~min}$, and none with a useful time resolution below $10 \mathrm{~min}$. A key aim of this paper is to improve on both of these metrics.

Tomographic testing techniques, also referred to in the literature as pre- and post-mortem tomography 
have, for example, been applied to resolve the formation of features in cements and concretes [14], including those resulting from hydration [15], sulphate attack [16], crack formation under load [17], and the effects of accelerated leaching [18]. However, in-situ tomographic analysis of cement hydration has mostly been limited to simplified model cases [12], despite demonstration of its value in fields including earth sciences [19] and biology [20-22].

It is extremely challenging to conduct in-situ analysis of the first hours of hydration of cements, as the anhydrous particles experience changes in morphology as reaction products are forming, as well as moving within the sample holder in the earlier stages of the time of testing, until solidification occurs. The authors have developed a new approach based on digital image cross-correlation to resolve contiguous microstructural volumes of interest in X-ray microtomography data for fluid suspensions that undergo significant microstructural changes over time [23]. This method enables tracking and segmentation of a particular cluster of particles in large sets of sequentially collected data, overcoming the complications due to particle sedimentation that otherwise hinder morphological analysis of cement hydrates insitu up to the time of setting of cementitious pastes.

In this study, time-resolved synchrotron X-ray microtomography has been applied, for the first time, to elucidate with high temporal and spatial resolution the microstructural changes taking place after mixing of Portland cement with water. Images are collected from the very earliest minutes of the hydration reaction; a period that has not previously been probed in in-situ tomographic studies of cement hydration, and during which reaction processes take place that can have a critical influence over the later-age durability and performance of these materials, for decades or more [24]. Direct correlation between the thermal output of the reaction and the spatial distribution of hydrous and anhydrous phases was identified, and the evolving properties of the pore structure determined.

\section{Materials and methods}

\section{Materials}

For this study, a Hanson Ribblesdale Works CEM I 52.5N Portland Cement (PC) meeting the EN 197-1
Table 1 The chemical composition of the Portland cement determined by X-ray fluorescence spectroscopy

\begin{tabular}{lr}
\hline Oxide & wt $\%$ \\
\hline $\mathrm{CaO}$ & 65.37 \\
$\mathrm{SiO}_{2}$ & 19.99 \\
$\mathrm{Al}_{2} \mathrm{O}_{3}$ & 4.55 \\
$\mathrm{SO}_{3}$ & 3.23 \\
$\mathrm{Fe}_{2} \mathrm{O}_{3}$ & 3.12 \\
$\mathrm{MgO}$ & 2.09 \\
$\mathrm{Minor}$ & 1.65 \\
\hline
\end{tabular}

Table 2 Particle size characterisation of the Portland cement material by laser diffractometry

\begin{tabular}{|c|c|}
\hline \multicolumn{2}{|l|}{ Parameter } \\
\hline$d_{\mathrm{x}(10)} / \mu \mathrm{m}$ & 2 \\
\hline$d_{\mathrm{x}(50)} / \mu \mathrm{m}$ & 14 \\
\hline$d_{\mathrm{x}(90)} / \mu \mathrm{m}$ & 42 \\
\hline Fineness $* / \mathrm{m}^{2} \mathrm{~kg}^{-1}$ & 376 \\
\hline Density $^{\dagger} / \mathrm{kg} \mathrm{m}^{-3}$ & 3.14 \\
\hline \multicolumn{2}{|c|}{${ }^{*}$ By the Blaine method } \\
\hline \multicolumn{2}{|c|}{$\begin{array}{l}\dagger \text { By helium expansion } \\
\text { pycnometry }\end{array}$} \\
\hline
\end{tabular}

standard [25], provided by Hanson Heidelberg Cement Group, was used. The oxide composition of this cement is presented in Table 1. Characterisation and compositional data are shown in Tables 1, 2 respectively. In this paper, some chemical reactions and compounds are described using cement chemistry notation, where $\mathrm{C}$ represents $\mathrm{CaO}, \mathrm{S}$ is $\mathrm{SiO}_{2}, \mathrm{H}$ is $\mathrm{H}_{2} \mathrm{O}$, and $\mathrm{A}$ is $\mathrm{Al}_{2} \mathrm{O}_{3}$. A hyphen indicates variable stoichiometry.

The particle size distribution was determined using a Malvern Instruments Mastersizer 3000 PSA with an Aero $S$ dry dispersion unit regulated to a feed pressure of $0.4 \mathrm{MPa}$. The particle sizes identified in this cement are reported in Table 2.

\section{Mixing and mounting}

Portland cement pastes were produced with a watercement ratio of 0.47 , which was the minimum required water content for production of a paste that could be loaded into a $2.0-\mathrm{mm}$ diameter borosilicate glass capillary and is within the typical limits provided by BS 8500 [26] for producing durable concretes. The resulting paste was compacted into the capillary using an oscillating head, though due to the risk of capillary wall fractures, complete compaction was not possible. Entrapped air resulted in settlement of the paste which was most prevalent within the first 
minutes of the reaction, and this was corrected in the measured data by the method presented in [23].

After mixing of the cement with water, the samples were immediately transferred into the beamline and mounted on the instrument stage. The time taken to mix, load and transfer the sample and initialise acquisition of the first scan was approximately $10 \mathrm{~min}$ from the moment the water contacted the anhydrous cement.

\section{Beamline measurement}

The experiment was performed at the XSD-IMG 2-BM beamline at the Advanced Photon Source (APS) [27] which provided a high-flux X-ray source which could capture microtomographic data at a potential rate of sub-seconds per tomogram. The beamline used a PCO Dimax sCMOS camera attached to a silicon scintillator for dynamic imaging, which resolved imaging data at $2.0 \mu \mathrm{m}$ per voxel, selected due to the ability to capture at a very high frame rate $(>1000 \mathrm{fps})$ and large internal buffer. Prior to acquisition of the first image, dark current and flat field images were captured which were used to account for consistent systematic noise and scintillator artefacts, respectively. During monitoring, 600 projections were captured per time point at a full frame $2000 \times 2000$-pixel resolution as the sample rotated through $180^{\circ}$. The total acquisition and refresh time of the instrument was less than $5 \mathrm{~s}$.

The temporal resolution achieved was limited primarily by the read-out time of the camera which was approximately $20 \mathrm{~min}$ on entire filling of the internal buffer, and this resulted in short breaks in capture during the experiment. The sample was monitored for approximately $13 \mathrm{~h}$ and $45 \mathrm{~min}$ at varying intervals.

\section{Reconstruction and data processing}

Data reconstruction was carried out off-line after collection using the TomoPy package [28] which allowed for batch-processing of large volumes of data.

Outliers were removed from both the unreconstructed dataset and open beam acquisitions, and the data were corrected for the dark current and flat field and written to disc in a binary format. The application of corrections resulted in floating point transmission values, and care was taken to ensure these remained consistently between 0 and 1 by verifying the maximum and minimum of each image. Stripe artefacts were removed from the dataset by the Fourier wavelet method [29].

The axis of rotation of the sample was then found visually at every fifth capture point. A correct location was indicated by the closure of circular or ring features within a reconstructed image; to test this, a slice was reconstructed in the vertical centre of each stack with the axis of rotation varied through a given range, which was refined to a precise value.

Phase contrast was extracted using a simultaneous phase and amplitude extraction from a phase contrast image algorithm [30] and was combined with the grayscale attenuation contrast with an empirically defined regularisation parameter value of 0.001 , with a baseline value set according to the standard beamline procedure. Reconstruction to a three-dimensional stack of images was then carried out using the Fourier grid reconstruction algorithm [31] which allows for full reconstruction on a desktop workstation within minutes. Following this, a unique volume was extracted from each reconstructed stack using image cross-correlation in a three-dimensional stack [23] and written to disc in a 16-bit nearly raw raster data (nrrd) format.

\section{Segmentation, meshing, and visualisation}

Once the subset for analysis had been located within the stack, the data were segmented by defining a consistent global set of greyscale thresholds for pores, hydrous, and anhydrous phases from the final scan data, and applying this to each three-dimensional volume. Thresholding in this manner is very commonly applied to segment data from both $\mu \mathrm{CT}$ [32] and back-scattered electron imaging [33] data, and global thresholding was opted for in the case of this study due to the simplicity of the segmentation, the ability to batch automate and rapidly debug the process where potentially large volumes of data were considered. The absolute threshold values were defined from the final scan and are provided in Fig. 1 alongside a histogram providing the distribution of grayscale values in the volume.

The threshold values were applied by loading data into a NumPy array and thresholding using a series of logical array operations which allowed for batchprocessing of the full set of nrrd files in a single shot, minimising the required human input and thereby 
Figure 1 An example histogram, segmentation grayscale values, and the segmentation of a single slice. Data are shown for the final scan, this being the point at which the threshold values are set. a Shows the segmented porosity phase, $\mathbf{b}$ the precipitate volume, $\mathbf{c}$ the surface hydrate, $\mathbf{d}$ the unreacted volume. The 16-bit grayscale histogram is shown in $\mathbf{e}$, original slice in $\mathbf{f}$. Values at 65,535 are included as unreacted materials.

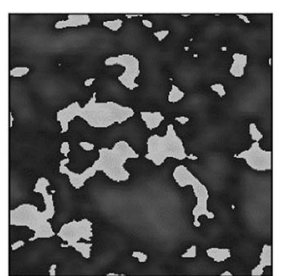

(a) Porosity

Maximum: 18504

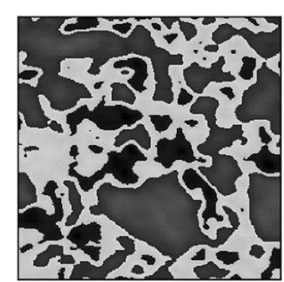

(b) Precipitate Maximum: 29524

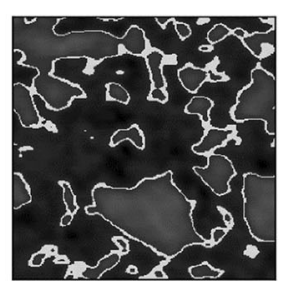

(c) Hydrate Maximum: 33709

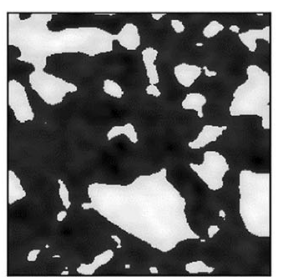

(d) Unreacted Minimum: 33709

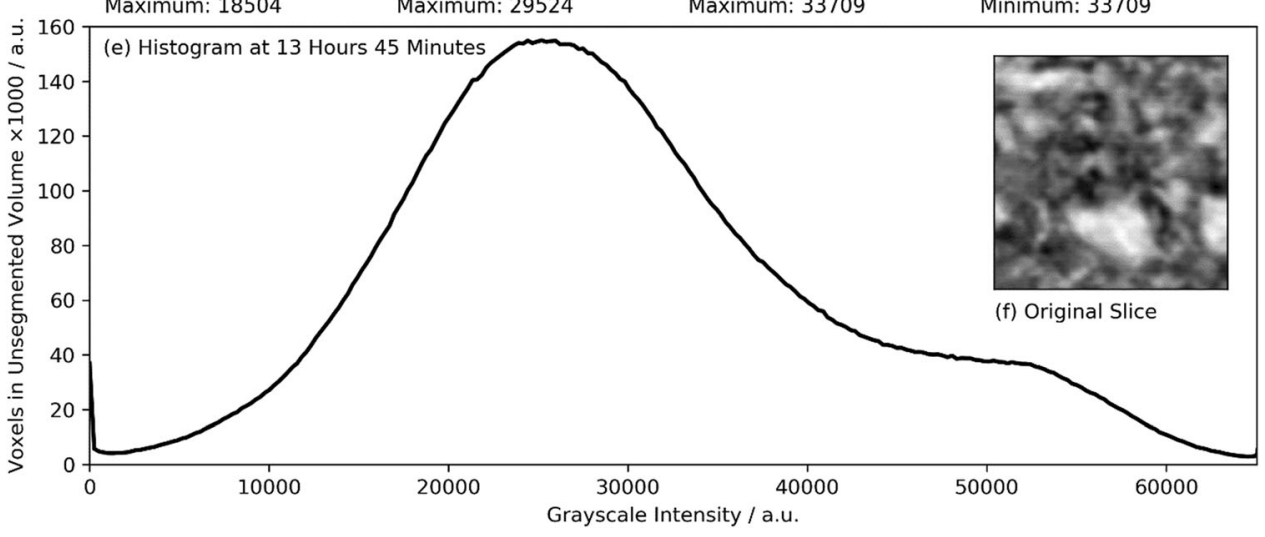

reducing any bias. Each stack was loaded into FijiimageJ [34], and a 3D stereolithography (stl) file exported [35] for each identified volumetric phase. Remeshing was performed using a Loop subdivision operation prior to the mesh being aligned to bounds with an equivalent size of $250 \times 250 \times 500 \mu \mathrm{m}$ (significantly exceeding the representative element volume for cement paste with the voxel size used here [36]) and ray-traced with indicative colourisation. An additional render camera was placed internally within the mesh and imagery to provide an internal view in a consistent position, which was adjusted only if the image was obscured by the internal geometry. The field of view of the main camera in conjunction with the camera position and the bounding box size was used to approximate the width of the field, $25 \mu \mathrm{m}$.

\section{Measuring the migration of precipitated material}

The ability to differentiate between the empty pore space and precipitating material made it possible to observe the migration of precipitates through the pore space, and in order to quantify this, the mean axial tortuosity of the empty pore structure (denoted here as $\tau$ ) in which no precipitates were identified was determined. The tortuosity of the pore structure is typically associated with the durability of the material and is a numerical (although perhaps arbitrary) descriptor of the complexity of transport paths through the microstructure [37]. Tortuosity increases with the complexity of the pore space, with a narrower and more restricted pore space or a pore space with a lower connectivity yielding a higher value, and it was therefore hypothesised that as precipitated material formed and constricted the empty space a higher tortuosity would result, with an inverse observation as agglomeration occurred.

Tortuosity is challenging to measure using conventional analytical techniques, and these typically require pre-conditioning of the sample and the use of significant assumptions regarding the geometry of the pore space [38]. Moreover, the duration of the analysis and requirement for pre-conditioning conflict with the rate at which the hydration reaction occurs, especially in the very early stages studied here. Sample tortuosity has also been previously related to the permeability [39] and chloride diffusion coefficients [40] in the literature, and these may also be able to give a reasonable assessment of the complexity of the pore structure. However, those methods are similarly incompatible with microtomographic assessment as carried out here.

Quantification of tortuosity using the random walk method on microtomographic data provides an analysis method which is fully compatible with the in-situ nature of the experiment where it is necessary to minimise interaction with the sample through 
either pre-conditioning or intermittent movement, and so was selected in this study. The tortuosity of the pore structure was determined using a random walk method implemented using a slight modification of a typical application of the pytrax Python module [41] which enabled a "hands-off" analysis at each point in the time-series. The random walk method simulates the time-dependent Brownian motion of a group of walkers placed at random within the empty pore space. The tortuosity value is directly related to the mean rate at which walkers are able to move away from their original starting location; walkers which collide with objects in their path (e.g. pore walls, defined by the precipitate boundary in the case of this experiment) are restricted in movement, lowering the rate at which they are able to move and thereby increasing the tortuosity. Although it is clear that pores below the voxel size threshold cannot be captured in this analysis, similar methods have in the past successfully been applied to study the tortuosity of porous media [37] and have more specifically provided positive results in studies of alkali-activated binders [42] and hardened cement pastes [43].

In this case, five volumes of $3,000,000$ voxels each were extracted from the reconstructed data, using the method presented in [23], excluding regions containing large fractions of entrapped air voids. Segmentation was carried out as described above, distinguishing the empty porosity (voxels containing little or no solid material), and the voxels that contained porous precipitates which were themselves more porous than the fully-formed hydrates or anhydrous cement grains. The calculation of tortuosity was carried out with $4 \times 10^{5}$ time points with 10,000 walkers running concurrently. The stride was set to unity and the analysis run in parallel on 8 cores, yielding a calculation of approximately $20 \mathrm{~min}$ per volume analysed. Walker displacement was determined in the three axes for least-squares fitting of a linear function to the mean squared displacement.

\section{Isothermal conduction calorimetry}

The cement hydration reaction was also followed by isothermal conduction calorimetry, performed using a TA Instruments TAM Air Microcalorimeter. The instrument was held at $25{ }^{\circ} \mathrm{C}$, matching the temperature of the hutch at the synchrotron. Paste samples were prepared in the same proportions detailed above, and were externally mixed for $2 \mathrm{~min}$, and placed into HDPE ampoules before being transferred immediately into the calorimeter. Data were recorded for the first $18 \mathrm{~h}$ of hydration, matching the time-scale used in the synchrotron experiment.

\section{Results and discussion}

\section{Hydration in the context of isothermal calorimetry}

Figure 2 shows the results obtained from isothermal calorimetric analysis of the hydration of Portland cement paste, including division of the signal into five characteristic heat flow features.

The approximate time periods of the hydration reaction identified from the calorimetric data are defined in Table 3. The peak thermal output occurs at around $8 \mathrm{~h}$, and there is no clear sulphate depletion point (which would have resulted in an additional peak). The absence of this additional feature appears to have resulted from masking of the sulphate depletion event by the main thermal output peak; a Bogue calculation [44] for the cement based on the data in Table 1 indicates a $\mathrm{C}_{3} \mathrm{~A}$ content of approximately $7 \%$, indicating that the cement is unlikely to have been so over-sulphated at $3.23 \% \mathrm{SO}_{3}$ (Table 1) as to delay the sulphate depletion peak beyond the $18 \mathrm{~h}$ experimental timeframe [45].

The initial very rapid heat release is related to particle wetting and the dissolution of highly reactive minor cement constituents, particularly alkali-containing sulphates such as syngenite $\mathrm{K}_{2} \mathrm{Ca}\left(\mathrm{SO}_{4}\right)_{2} \cdot \mathrm{H}_{2} \mathrm{O}$ [46]. This occurs alongside dissolution of highly reactive defect regions on the $C_{3} S$ surface, which dissolve to release calcium and silicon ions into the aqueous phase [47]. The subsequent reduction in the rate of the reaction to a period of low heat output, termed the "induction" or "dormant" period (period 2 in Fig. 2), the nature of which remains somewhat contentious in the literature. This time period, during which heat release is relatively low, has been associated by some researchers with the formation of a metastable barrier across the surface of anhydrous alite grains, while others favour a theory based on dissolution rate control by the degree of undersaturation as this approaches the point at which bulk precipitation of hydrate products would commence [1]. 


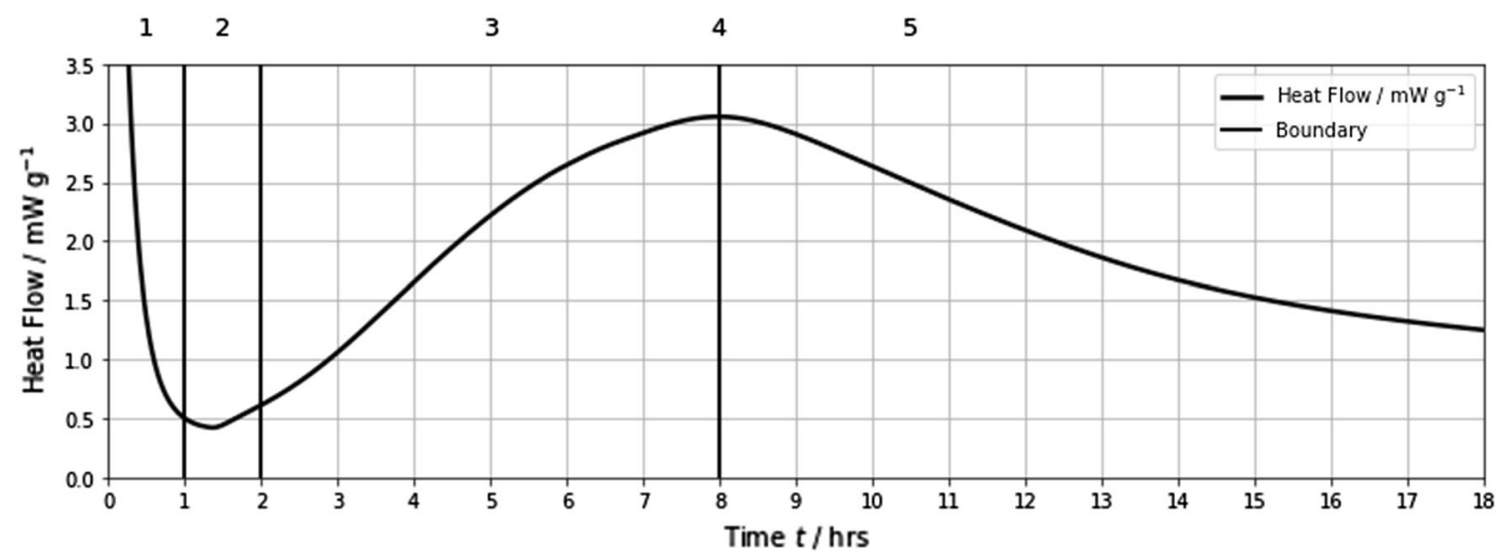

Figure 2 The hydration of Portland cement observed by isothermal conduction calorimetry. The time periods labelled 1-5 are identified as characteristic features of the heat flow representing distinct stages of the hydration reaction process.

Table 3 The approximate periods in the hydration reaction sequence identified by isothermal conduction calorimetry

\begin{tabular}{lll}
\hline Period & Start/h & End/h \\
\hline 1 Dissolution & 0 & 1 \\
2 Induction & 1 & 2 \\
3 Acceleration & 2 & 7 \\
4 Peak & 8 & - \\
5 Deceleration & 8 & $13.75^{*}$ \\
\hline
\end{tabular}

*Time of final scan

The metastable barrier hypothesis describes the formation of an initial hydrate product layer that inhibits the contact of free water with the anhydrous cement and passivates the surface, before the barrier becomes breached at the end of the induction period [48], allowing for the growth of hydrates during acceleration (period 3 in Fig. 2) [49, 50]. This is a hypothesis that is claimed to describe the slowing of the reaction into the induction period (from period 1 to 2); the barrier would prevent contact between the mix water and the anhydrous cement. However, results captured with modern instrumentation at a very high resolution show the formation of no such continuous layer at the interface [51] and only the formation of small regions of fibrillar calcium silicate hydrate (C-S-H) deposited with little interconnectivity, whereas such a reaction mechanism would require the surface to be entirely coated. On this basis, and also through studies of tricalcium silicate hydration under varying conditions, the hypothesis of a metastable barrier has received significant recent criticism [1]. The current study, using an in-situ tomographic approach and studying cement pastes with realistic water/cement ratios, offers the possibility to gain more insight into these mechanisms, although at a lower spatial resolution than some surface-sensitive spectroscopic or microscopic techniques.

\section{Early dissolution and the induction period}

Figure 3 shows the development of hydrates at the interface between anhydrous cement and mix water, during the first $90 \mathrm{~min}$ of the reaction. These data show the formation of a narrow and disconnected layer by ten minutes, which interconnects, thickens, and expands slightly by $30 \mathrm{~min}$.

Within the first minutes of measurement, we observed the formation of a disconnected layer of moderate-density (hydrous) material at the cement particle surface, consistent with results presented in [51]. Although our spatial resolution is significantly lower than that provided by the cryo-SEM used in that study, the formation of proximate regions of surface hydrates at this time will have resulted in some of the reconstructed voxels adjacent to the anhydrous particle surface containing sufficient solids to become segmented as hydrate products.

Although it is not possible to carry out a chemical analysis using these tomography data, it is hypothesised that regions of hydrous silicates, potentially consisting either of disordered $\mathrm{C}-\mathrm{S}-\mathrm{H}$ as in the (tensof-nanometres thickness) membrane identified in [51], or by hydroxylation of the silicate sites near the surface of the $\mathrm{C}_{3} \mathrm{~S}$ as identified in [3], has formed a partial coating at the interface between the reacting 


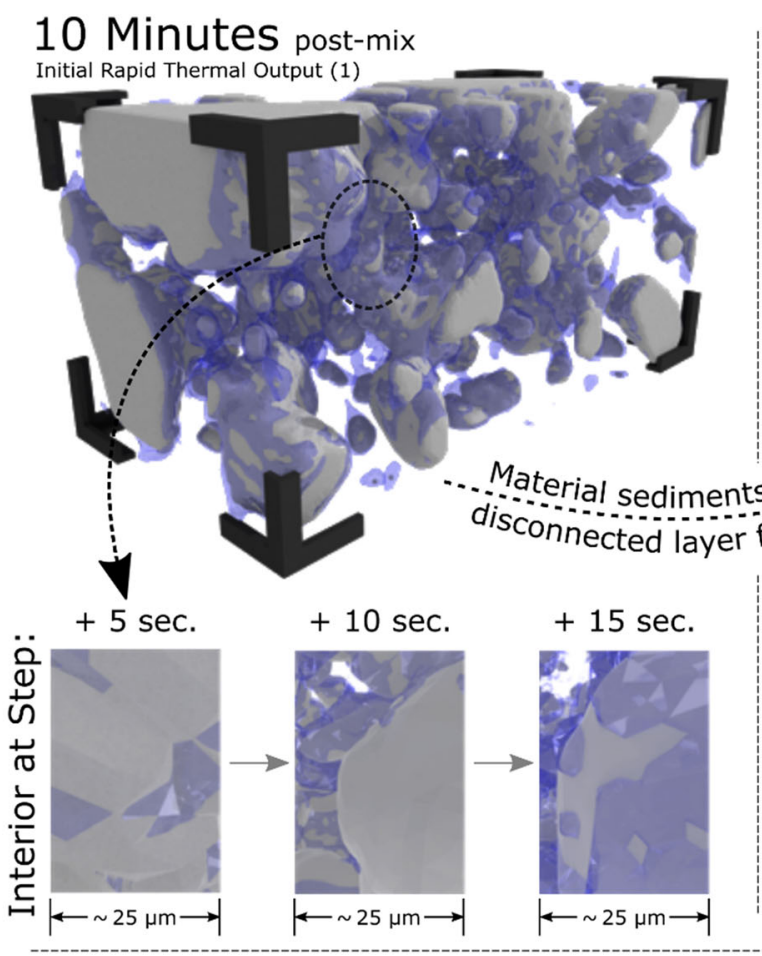

30 Minutes post-mix
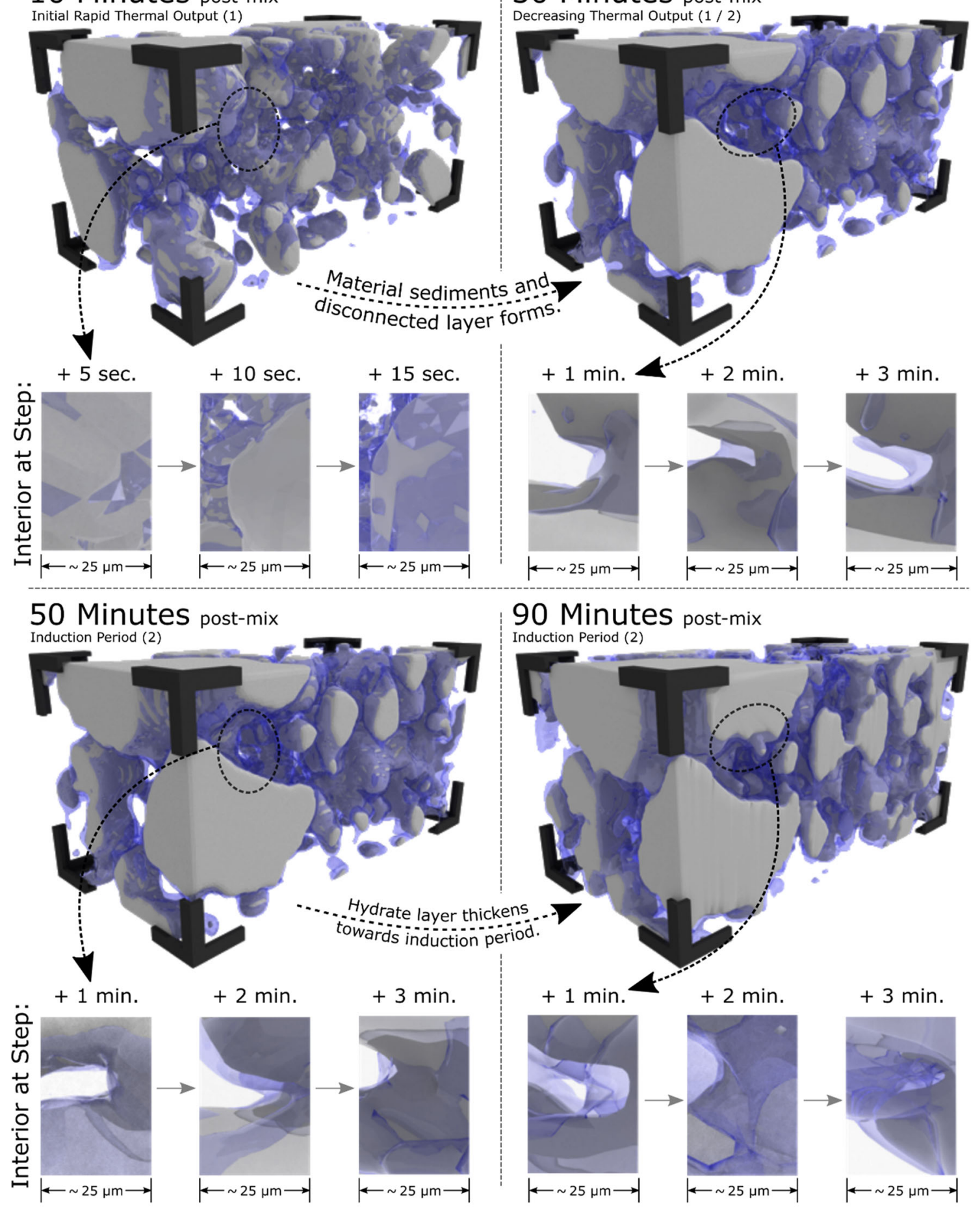

\section{Unreacted - \\ Hydrate - \\ Bound Regions $250 \times 250 \times 500 \mu \mathrm{m}$}

Figure 3 The formation of solid hydrated phases during the first $90 \mathrm{~min}$ of the reaction. Numbers shown in parentheses in each section of the graphic indicate the reaction stage (defined in Fig. 2) corresponding to each time point shown.

$\mathrm{C}_{3} \mathrm{~S}$ grains and the mix water. These data do not demonstrate whether or not this is essential in controlling the reaction during the induction period, as other authors are increasingly contending that the rate-controlling mechanism in this stage of the reaction is the degree of undersaturation of the aqueous 
phase [1]. However, and importantly, these data provide clear evidence for the development of hydrous regions on the cement grain surfaces even at this early stage of the cement hydration process.

In addition to the formation of these small siliceous hydrate regions on or near the surface, the hydrous calcium aluminium sulphate phase ettringite is known to form very soon after mixing of cement with water [24], by hydration of $\mathrm{C}_{3} \mathrm{~A}$ from the clinker in the presence of sufficient dissolved sulphate ions [24]. The presence of ettringite is typically indicated by a needle-like structure within the solid product [33]. However, due to the challenge of segmenting phases with closely matching grayscale intensities (e.g. ettringite and $\mathrm{C}-\mathrm{S}-\mathrm{H}$ ) without adding a tracer element [52], and under the constraints of an in-situ tomographic approach, it was not possible to specifically identify ettringite needles within any of the reconstructions here.

The formation of the empty pore volume, and of porous precipitates, is shown in Fig. 4, while the tortuosity values determined for the pore volumes are shown in Fig. 5. The tortuosity of the solid phase regions was also determined, and closely tracked the pore network tortuosity except in the first minutes of hydration (due to the low connectivity of the solid network at that time), so the discussion here is based on pore network tortuosity values.

During the initial period of heat release, the solution rapidly reached saturation with respect to calcium and silicate-bearing phases, causing small regions of hydrate (appearing as flecks within the reconstructions) to precipitate within the fluid-filled pore volume, controlled by the degree of undersaturation $[53,54]$.

Precipitates are observed to form immediately adjacent to the cement particle surfaces, suggesting that an ionic concentration gradient had formed within the pore solution, with a higher concentration close to the surfaces of the anhydrous material leading to a higher local supersaturation in this region.

During the induction period of cement hydration (50-90 min in Fig. 5), there is a weakly increasing trend in pore tortuosity. Through the induction period, the pore fluid reaches then exceeds saturation with respect to $\mathrm{C}-\mathrm{S}-\mathrm{H}$ and/or $\mathrm{Ca}(\mathrm{OH})_{2}$. When supersaturation is reached, the induction period ends, and further precipitation within the fluid-filled space commences, leading the tortuosity to begin to increase as the induction period is completed.
The acceleration, peak, and deceleration of the reaction

The mechanism which triggers the end of the induction period remains a question of open debate in the field; the assessment of Scrivener et al. [1] indicated that neither diffusional restriction, nor impingement of hydrate products, nor the dissolution of small (high surface area) cement grains, can fully explain or control the transition from the acceleration to the deceleration period. In the acceleration stage, there is a rapid increase in the exothermic output of the reaction, marked as period 3 on the calorimetric trace (Fig. 2). Tomographic imaging data corresponding to this period are shown in Fig. 6 for the solid phase and Fig. 7 for the void space, while Fig. 5 describes the evolution of tortuosity.

During the acceleration of the reaction (period 3), a low-density product began to form at the interface between cement and pore fluid, and thickened gradually as a result of both inward growth towards the centre of the original grain ("inner product") and the deposition of precipitating material on the surface of this inner layer, in the originally fluid-filled space ("outer product"). The high temporal resolution and the use of the particle-tracking algorithm [23] in this work provide confidence that the same cement grains were able to be identified in successive scans of the material during the entire process of hydration, despite settlement and slight sedimentation that took place at early age. Considering the spatial resolution of these measurements, it was not possible to resolve the morphology of the product forming on the surface, although microscopic analysis has shown that this is often a fibrous growth [55].

The onset of the acceleration period is shown in Fig. 6 to involve the bulk growth of precipitated hydrates onto and into the surfaces of the cement grains, accompanied by an increase in pore tortuosity (Fig. 5) as the solid phase network starts to bridge gaps between neighbouring cement grains and tends towards percolation [56].

By $6 \mathrm{~h}$, a thickening band of hydrate has formed upon the surface of the cement grains, and the inner and outer products can be described as hydrate shells [57]. These then interlock, causing stiffening of the paste and the formation of the solid matrix, both from agglomeration at the edge of the hydrating layer, and from the growth of the inner layer inwards to bring 

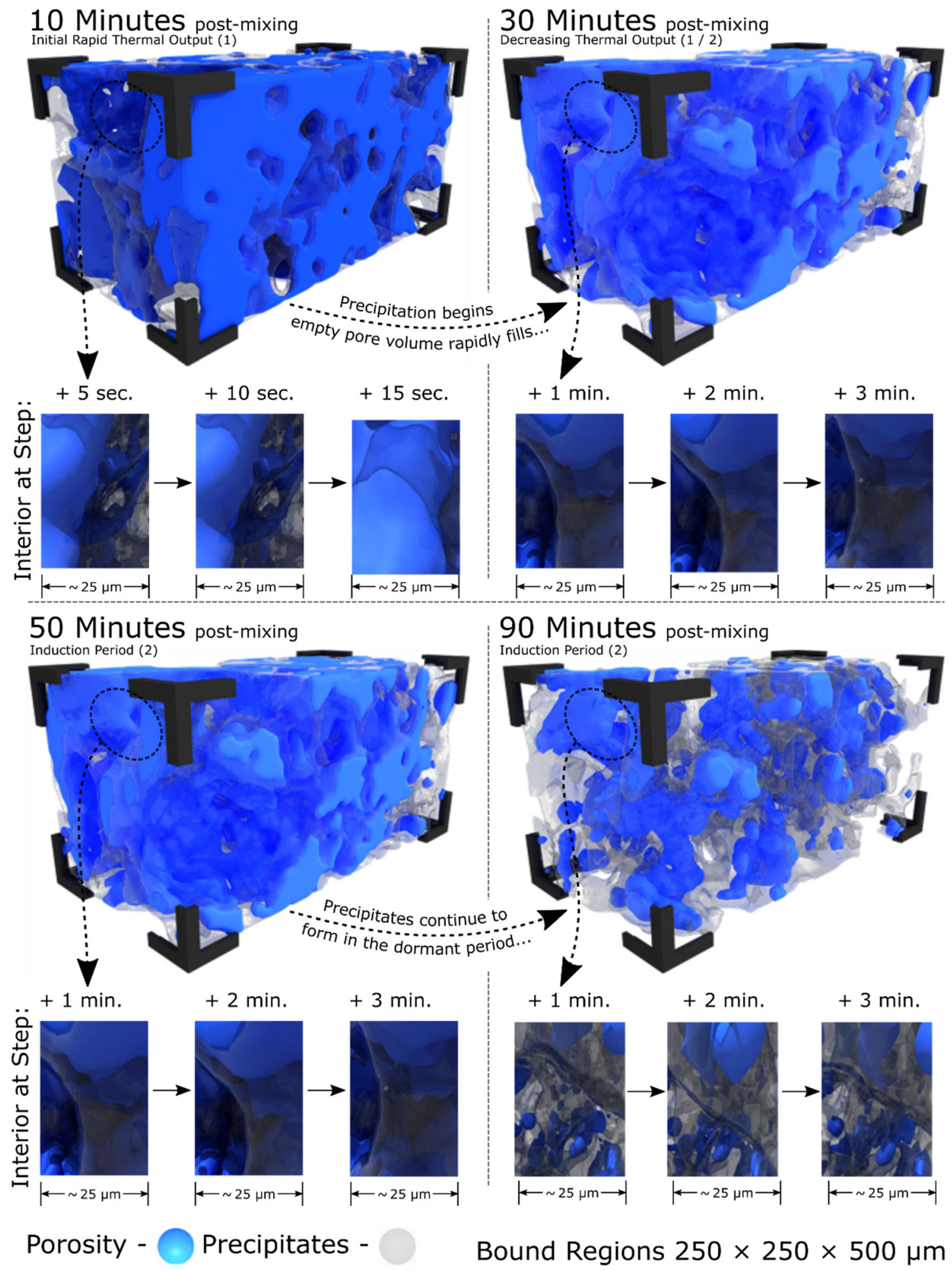

Figure 4 The formation of the pore structure across the first 90 min of the reaction. Empty porosity is shown in blue and precipitate shown in grey. 


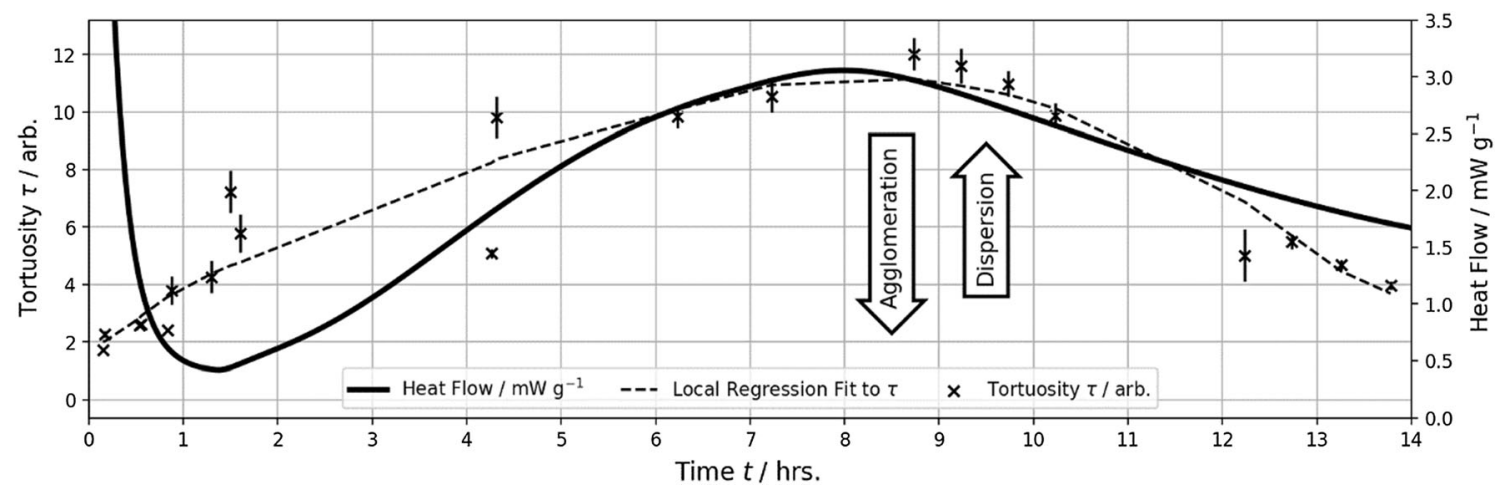

Figure 5 The tortuosity of the precipitate volume as calculated from the tomographic reconstructions. This is displayed alongside the isothermal calorimetric trace measured for the same cement

continuing close contact between hydrous and anhydrous constituents. Hu et al. [15] showed using X-ray nanotomography that there was a density gradient, on sub-micron length scales, within the hydration products that formed on the surfaces of hydrating $\mathrm{C}_{3} \mathrm{~S}$ grains. Our results are consistent with that theory, although collected at lower spatial resolution to enable the time-resolved nature of this study.

Eventually the surface of the cement particle becomes entirely coated and dissolution begins to slow at the peak thermal output (period 4), and beyond into the deceleration period (period 5). The precise nature of the mechanism responsible for the timing of the peak and the slope of the post-peak deceleration has also been contentious during the past decade or more, and it appears that a combination of space-filling, water-exhaustion, and diffusion barrier effects is needed to fully describe behaviour in this timeframe [1]. The observation here of an increasingly dense and thick surface layer of hydrates is consistent with the current state of the art in understanding the causes and mechanisms of this deceleration process. The progressive densification of the outer product hydrate shell is particularly important in describing mass transport limitations imposed by the newly-formed hydrates and is more clearly observable from the tomographic data in Fig. 6 than by other (usually two-dimensional) analytical techniques described in the literature. This has not been identified in such detail in past tomographic studies of cement hydration, and so the results presented here provide a new depth of information to describe this process in three spatial dimensions. hydration process. Tortuosity data shown are the mean of five tortuosity calculations across five volumes of interest, segmented at random from the stack.

The formation of hydrates at the time of capture of the final tomographic dataset (13 h $45 \mathrm{~min}$ ) is shown in the lower part of Fig. 6. Hydrates have formed to a significant degree, both on the surfaces of cement particles and isolated within the pore structure (as also seen in Fig. 7) although the total degree of hydration of the cement remains fairly low at this time. As hydrates have been deposited, the access of free water to the unreacted clinker grain surfaces has been inhibited. The water/cement ratio of these pastes (0.47) is sufficiently high that the water reservoir will not yet have been depleted by hydration reactions at this relatively early stage of the reaction process, but the transport of this water to the particle surface is significantly impeded. The result is the slowing of precipitation and a gradual reduction in the thermal output as the layer thickens, blocking access of water to the cement particle surfaces. Interlocking and adhesion of these hydrates fundamentally results in the rapid strength gain of the material across the first days of the hydration reaction.

The calculated tortuosity (Fig. 5) decreases during this time, which is attributed to the apparent closure of the smaller pores considering the voxel size used here (approximately $2 \mu \mathrm{m}$ ); the smallest pores move out of the range that is accessible using this technique and become sub-micron in size. This reduces the calculated tortuosity of the pore network as a whole. This observation of decreasing tortuosity with decreasing porosity is somewhat counter-intuitive, as tortuosity is widely observed to increase at decreasing pore volume fractions. However, in a case such as is observed here, with a multi-modal pore size distribution dominated by large inter-particle spaces 


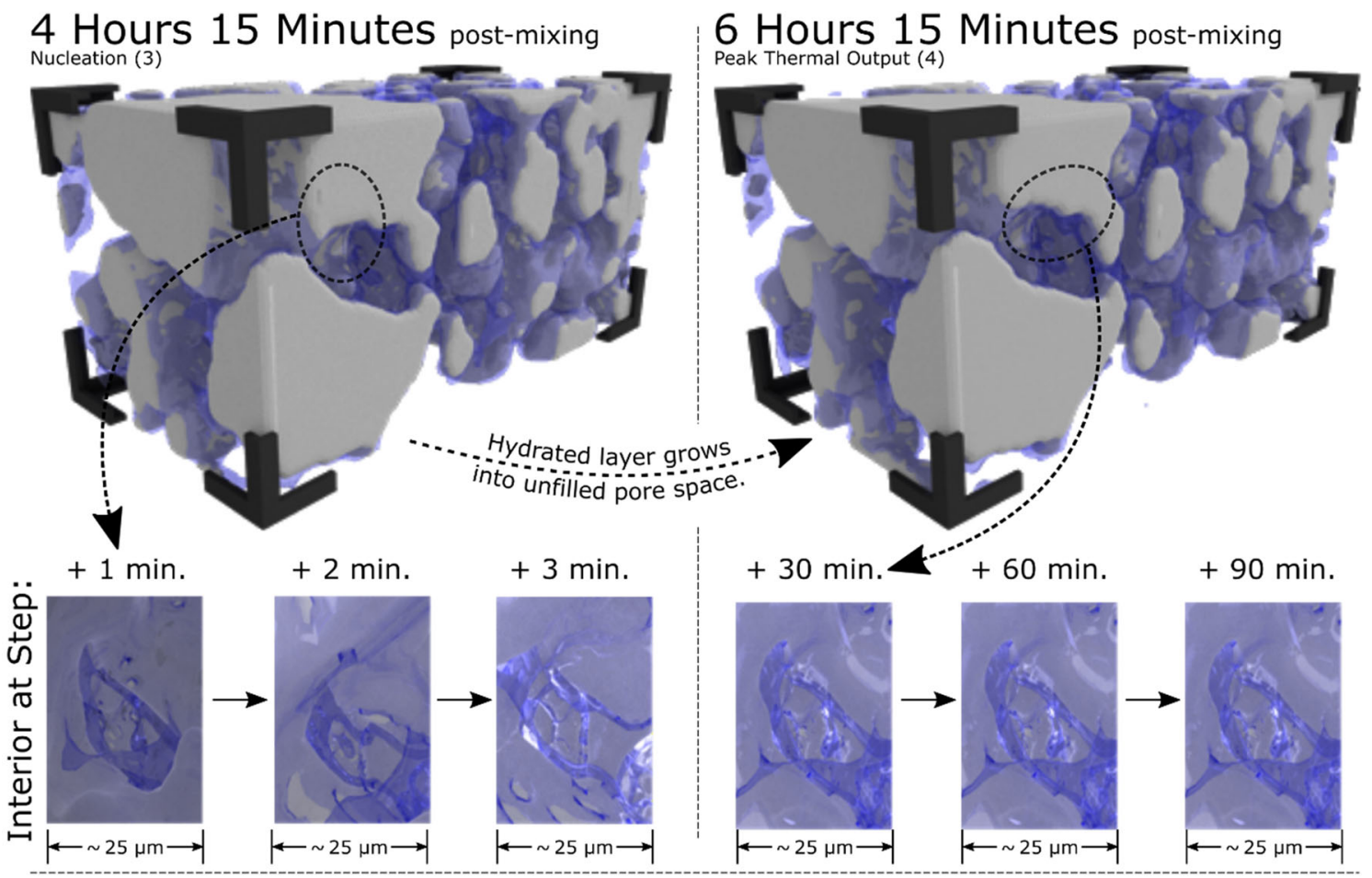

9 Hours 15 Minutes post-mixing

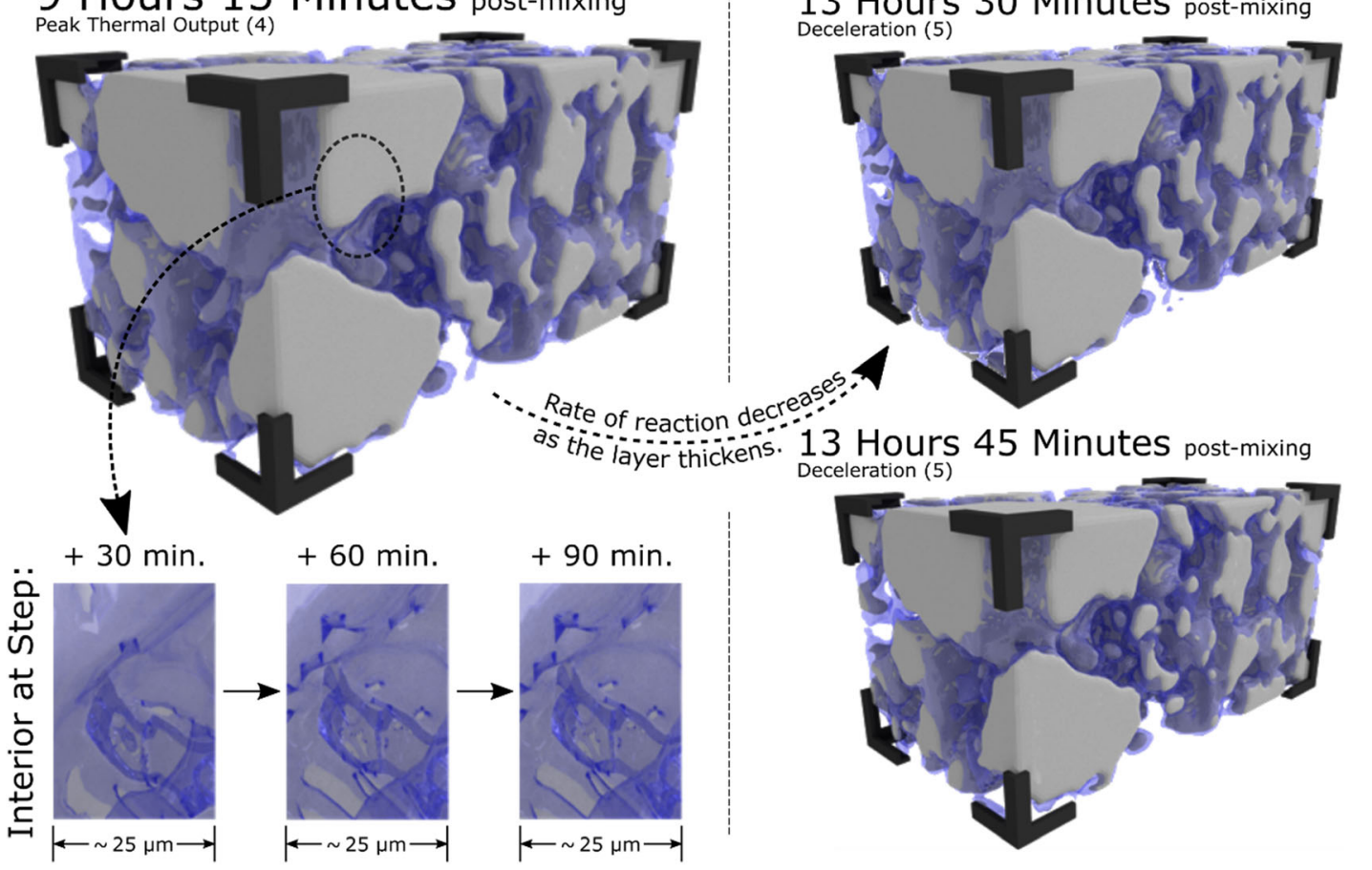

\section{Unreacted - Hydrate - Bound Regions $250 \times 250 \times 500 \mu \mathrm{m}$}

Figure 6 The formation of solid hydrated phases during the remaining hours of the reaction. Numbers shown in parentheses in each section of the graphic indicate the reaction stage (defined in Fig. 2) corresponding to each time point shown. 

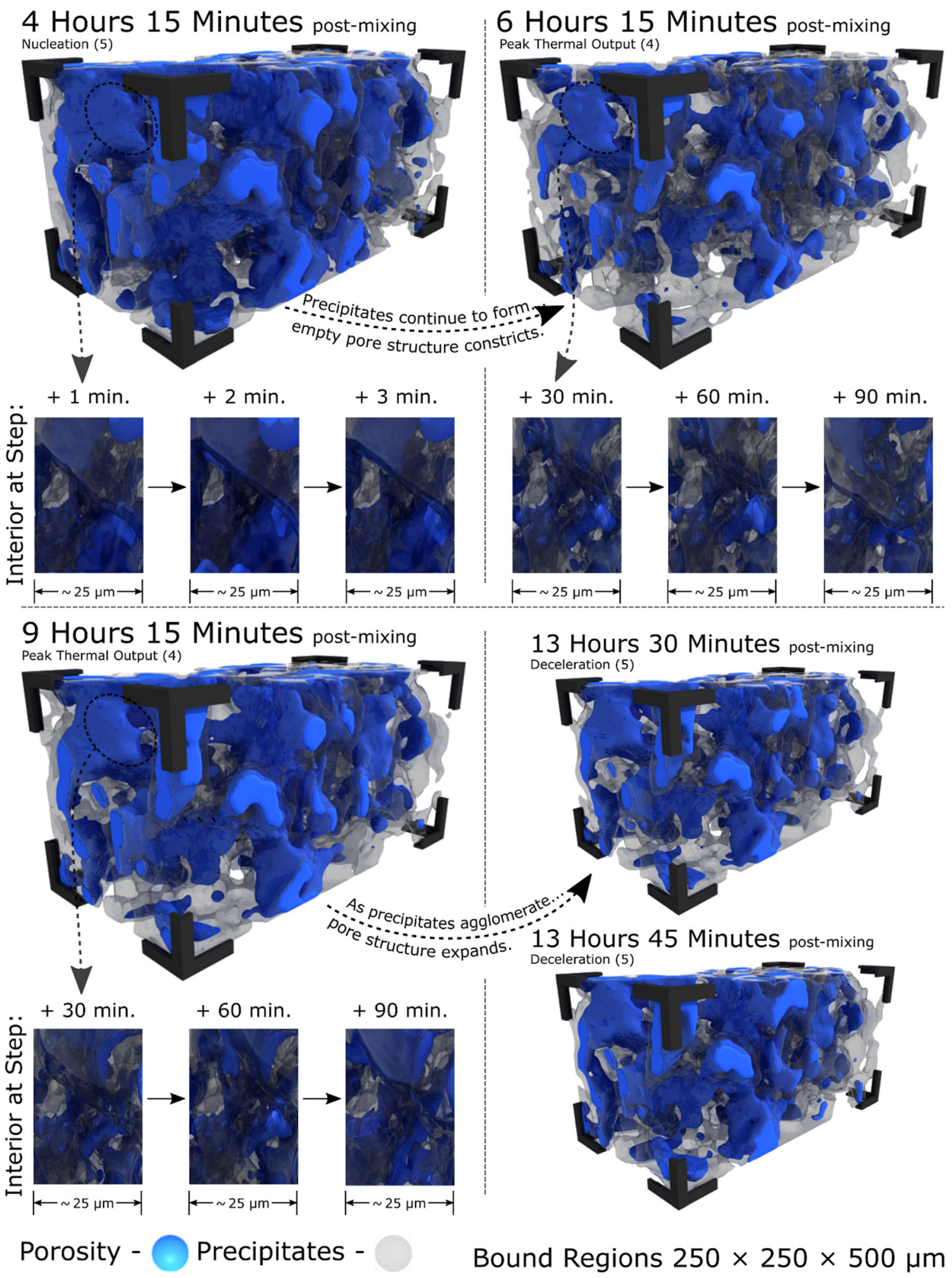

Figure 7 The formation of the pore structure across the latter $12 \mathrm{~h}$ of the reaction studied. Empty porosity is shown in blue and precipitates shown in grey. 
and smaller inter-hydrate pores, a close-to-uniform growth of hydrate products on all surfaces causing the apparent closure of the smaller pore fraction can decrease overall tortuosity by leaving only the larger, less-tortuous pores available for transport. This appears to be the case here. It would be expected that further ongoing hydration, resulting in the refinement of the remaining larger pores, would then give the expected later-age increase in tortuosity to the higher values recorded in the literature (e.g. 3 at 2 days, and 9 at 28 days, recorded by Promentilla et al. [43] for Portland cement paste at water/ cement $=0.50$ ).

\section{Linking the physical processes}

It is challenging to reach precise conclusions regarding the chemical processes involved in the cement hydration reaction using tomographic imaging alone. However, the ability to observe the threedimensional microstructural evolution of cement

\section{Regions of disconnected surface hydrate form.}

2. Precipitates form in pore structure.

3. Precipitates agglomerate on the surface.

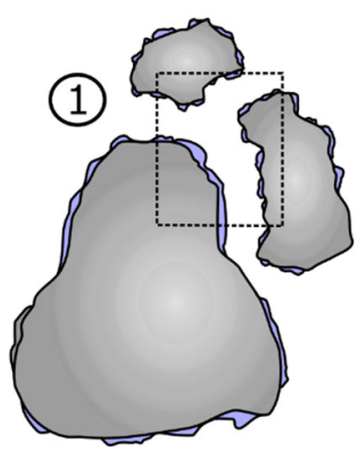

(2)

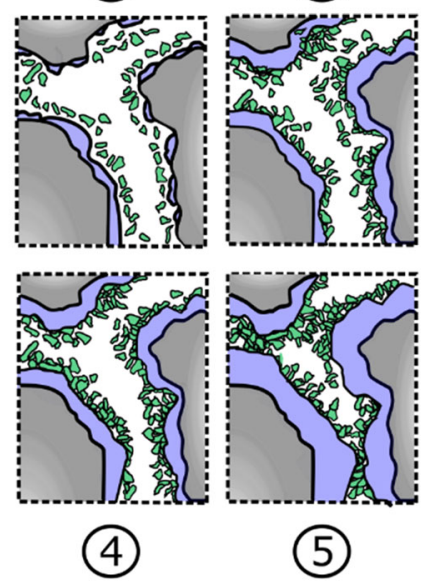

\section{Surface hydrates grow and agglomeration} increases empty pore volume.

\section{Interlock and reduction in pore volume.}

Figure 8 The formation of porosity, precipitate, and interface hydrate, and densification of hydration product in a Portland cement, illustrated schematically based on the tomographic data collected in this study. paste as a function of time enables discussion of the mechanism of microstructural development that leads to setting of the material, which we show in Fig. 8. This schematic, and the text below, draw together the discussion and analysis above into an improved degree of insight into cement hydration in four dimensions (three spatial and one temporal).

In the initial stage of the reaction (period 1 as defined in Fig. 2), rapidly-soluble components dissolve, and small volumes of surface hydrate form, but these do not yet percolate, cover the particle surfaces, or result in the interlocking (percolation and stiffening) of the cementitious paste. Small precipitates also form within the fluid-filled regions, potentially through hydration of very small clinker grains that are not directly observable at the spatial resolution of analysis here; these do not agglomerate at this point.

During the induction period, period 2, the thermal output of the reaction significantly decreases, although throughout this period dissolution continues, as does the growth of the hydrate product layer. The hydrating interface continues to thicken but does not yet cause inter-particle bridging between initiallyseparate cement grains.

Period 3 is the acceleration period, when the formation of hydrate products is at its most rapid, and the outer and inner hydrate product regions become evident on and around the cement particle-mix water interface. The low-density outer product grows outwards, and the denser inner product layer grows inwards, to form concentric shells distinguishable by a density gradient. The small inter-hydrate pores and larger inter-particle pores form an increasingly tortuous fluid-filled pore network.

Interconnections between the outer product layers growing from initially-separated cement grains begins to occur during period 3 and into period 4 (the peak heat flow), while further precipitation and agglomeration occurs. As the system evolves into the deceleration period, the smallest pores appear to be refined into a sub-micron regime, leading to an apparent reduction in tortuosity when determined using a tomographic approach with a voxel size that is larger than this. The growth and densification of the inner product causes the reaction to slow, the regions of outer product closer to the interface with the inner product densify, and the bulk outer product regions continue to fuse to each other as they percolate, resulting in a rigid structure. 


\section{Conclusions}

In this study, in-situ X-ray microtomography has been used to gain new insight into the process of hydration, setting and hardening during the first hours of hydration of Portland cement. A new and strong relationship has been identified between the stages of reaction identified by isothermal calorimetry and the tortuosity of the pore network as it develops during cement hydration, which is only directly identifiable via in-situ tomographic analysis.

When cement is brought into contact with water, hydrated phases are observable on cement grain surfaces from very early in the reaction process. This has not previously been observed in three dimensions at the time resolution applied here, and so this work provides an advance in the characterisation and understanding of this aspect of cement hydration. Although it is not possible to explicitly define whether the observed hydrates are formed by precipitation or by hydroxylation of a surface layer on the cement grains, such layers form during the induction period and may influence the continuing rate of reaction. With continued hydration, the hydrate products gradually begin to grow both from particle surfaces into the initially fluid-filled region, and also into the space originally occupied by the cement particle, forming an observable density gradient within the microstructure.

During the acceleration period, the generation of a percolated solid structure which can bear mechanical load begins via interconnection of agglomerated lowdensity outer hydrates, which are able to be visualised directly in three dimensions in the results presented here. These hydrates then densify as hydration continues. This eventually solidifies the structure into a hardened porous matrix, with pores forming in regions where hydrates have not sufficiently grown to fill the voids present between particles. The result is the porous medium known as hardened cement paste, which forms the key binding phase in concretes throughout the built environment.

\section{Funding}

This work was carried out as a part of APS beamtime proposal GUP 40230 on the 2-BM-A,B endstation. This research used resources of the Advanced Photon
Source, a US Department of Energy (DOE) Office of Science User Facility operated for the DOE Office of Science by Argonne National Laboratory under Contract No. DE-AC02-06CH11357. This project is part funded by the Nuclear Decommissioning Authority (NDA) of the UK, and the Engineering and Physical Sciences Research Council (EPSRC), through a CASE Award studentship. Participation of S.A. Bernal in this study was sponsored by EPSRC through EC fellowship EP/R001642/1.

\section{Declarations}

Conflict of interest The authors declare that they have no conflict of interest.

Open Access This article is licensed under a Creative Commons Attribution 4.0 International License, which permits use, sharing, adaptation, distribution and reproduction in any medium or format, as long as you give appropriate credit to the original author(s) and the source, provide a link to the Creative Commons licence, and indicate if changes were made. The images or other third party material in this article are included in the article's Creative Commons licence, unless indicated otherwise in a credit line to the material. If material is not included in the article's Creative Commons licence and your intended use is not permitted by statutory regulation or exceeds the permitted use, you will need to obtain permission directly from the copyright holder. To view a copy of this licence, visit http://creativecommons.org/licen ses/by/4.0/.

\section{References}

[1] Scrivener K, Ouzia A, Juilland P, Kunhi Mohamed A (2019) Advances in understanding cement hydration mechanisms. Cem Concr Res 124:105-823. https://doi.org/10.1016/j.cemc onres.2019.105823

[2] Thomas JJ, Jennings HM (2006) A colloidal interpretation of chemical aging of the $\mathrm{C}-\mathrm{S}-\mathrm{H}$ gel and its effects on the properties of cement paste. Cem Concr Res 36:30-38. http s://doi.org/10.1016/j.cemconres.2004.10.022

[3] Pustovgar E, Sangodkar RP, Andreev AS, Palacios M, Chmelka BF, Flatt RJ, d'Espinose de Lacaillerie J-B (2016) Understanding silicate hydration from quantitative analyses of hydrating tricalcium silicates. Nat Commun 7:10952. h ttps://doi.org/10.1038/ncomms 10952 
[4] Ioannidou K, Kanduč M, Li L, Frenkel D, Dobnikar J, Del Gado E (2016) The crucial effect of early-stage gelation on the mechanical properties of cement hydrates. Nat Commun 7:12106. https://doi.org/10.1038/ncomms12106

[5] Thompson SP, Parker JE, Potter J, Hill TP, Birt A, Cobb TM, Yuan F, Tang CC (2009) Beamline I11 at Diamond: a new instrument for high resolution powder diffraction. Rev Sci Instrum 80(7):075107. https://doi.org/10.1063/1.3167217

[6] Thompson SP, Parker JE, Marchal J, Potter J, Birt A, Yuan F, Fearn RD, Lennie AR, Street SR, Tang CC (2011) Fast $\mathrm{X}$-ray powder diffraction on $\mathrm{I11}$ at Diamond. J Synchrotron Radiat 18:637-648. https://doi.org/10.1107/ S0909049511013641

[7] Fusseis F, Xiao X, Schrank C, De Carlo F (2014) A brief guide to synchrotron radiation-based microtomography in (structural) geology and rock mechanics. J Struct Geol 65:1-16. https://doi.org/10.1016/j.jsg.2014.02.005

[8] Buffiere JY, Maire E, Adrien J, Masse JP, Boller E (2010) In situ experiments with $\mathrm{X}$ ray tomography: an attractive tool for experimental mechanics. Exp Mech 50:289-305. http s://doi.org/10.1007/s11340-010-9333-7

[9] Snellings R, Mertens G, Adriaens R, Elsen J (2013) In situ synchrotron X-ray powder diffraction study of the early age hydration of cements blended with zeolitite and quartzite fines and water-reducing agent. Appl Clay Sci 72:124-131. h ttps://doi.org/10.1016/j.clay.2012.12.002

[10] Aranda MAG (2016) Recent studies of cements and concretes by synchrotron radiation crystallographic and cognate methods. Crystallogr Rev 22:150-196. https://doi.org/10.10 80/0889311X.2015.1070260

[11] Bullard JW, Jennings HM, Livingston RA, Nonat A, Scherer GW, Schweitzer JS, Scrivener KL, Thomas JJ (2011) Mechanisms of cement hydration. Cem Concr Res 41:1208-1223. https://doi.org/10.1016/j.cemconres.2010.09. 011

[12] Moradian M, Hu Q, Aboustait M, Ley MT, Hanan JC, Xiao X, Rose V, Winarski R, Scherer GW (2019) Multi-scale observations of structure and chemical composition changes of portland cement systems during hydration. Constr Build Mater 212:486-499. https://doi.org/10.1016/j.conbuildmat.2 019.04 .013

[13] Liu K, Cheng X, Ma Y, Gao X, Yu Y, Zhang C, Guo X, Zhuang J (2020) Visualization and quantification of pore structure of oil-well cement slurry in liquid-solid transition stage using high-resolution computed tomography. Cem Concr Compos 111:103633. https://doi.org/10.1016/j.cemco ncomp.2020.103633

[14] Brisard S, Serdar M, Monteiro PJM (2020) Multiscale X-ray tomography of cementitious materials: a review. Cem Concr
Res 128:105824. https://doi.org/10.1016/j.cemconres.2019. 105824

[15] Hu Q, Aboustait M, Kim T, Ley MT, Hanan JC, Bullard J, Winarski R, Rose V (2016) Direct three-dimensional observation of the microstructure and chemistry of $\mathrm{C}_{3} \mathrm{~S}$ hydration. Cem Concr Res 88:157-169. https://doi.org/10. 1016/j.cemconres.2016.07.006

[16] Bentz D, Martys NS, Stutzman P, Levenson M, Garboczi E, Dunsmuir J, Schwartz L (1994) X-ray microtomography of an ASTM C109 mortar exposed to sulfate attack. MRS Sympos Proc 370:77-82. https://doi.org/10.1557/PROC-37 $0-77$

[17] Shah SP, Choi S (1999) Nondestructive techniques for studying fracture processes in concrete. Int $\mathrm{J}$ Fract 98:351-309. https://doi.org/10.1023/A:1018620008780

[18] Burlion N, Bernard D, Chen D (2006) X-ray microtomography: application to microstructure analysis of a cementitious material during leaching process. Cem Concr Res 36:346-357. https://doi.org/10.1016/j.cemconres.2005.04. 008

[19] Bultreys T, De Boever W, Cnudde V (2016) Imaging and image-based fluid transport modeling at the pore scale in geological materials: a practical introduction to the current state-of-the-art. Earth-Sci Rev 155:93-128. https://doi.org/ 10.1016/j.earscirev.2016.02.001

[20] Faulwetter S, Vasileiadou A, Kouratoras M, Dailianis T, Arvanitidis C (2013) Micro-computed tomography: introducing new dimensions to taxonomy. ZooKeys 263:1-45. h ttps://doi.org/10.3897/zookeys.263.4261

[21] Walker SM, Schwyn DA, Mokso R, Wicklein M, Müller T, Doube M, Stampanoni M, Krapp HG, Taylor GK (2014) In vivo time-resolved microtomography reveals the mechanics of the blowfly flight motor. PLoS Biol. https://doi. org/10.1371/journal.pbio.1001823

[22] Lowe T, Garwood RJ, Simonsen TJ, Bradley RS, Withers PJ (2013) Metamorphosis revealed: time-lapse three-dimensional imaging inside a living chrysalis. J R Soc Interface 10(84):20130304. https://doi.org/10.1098/rsif.2013.0304

[23] Vigor JE, Bernal SA, Xiao X, Provis JL (2020) Automated correction for the movement of suspended particulate in microtomographic data. Chem Eng Sci 223:115736. https://d oi.org/10.1016/j.ces.2020.115736

[24] Schlegel M-C, Sarfraz A, Müller U, Panne U, Emmerling F (2012) First seconds in a building's life: in situ synchrotron X-ray diffraction study of cement hydration on the millisecond timescale. Angew Chem Int Ed 51:4993-4996. h ttps://doi.org/10.1002/anie.201200993

[25] British Standard Institute (2011) BS EN 197-1: Cement. Composition, specifications and conformity criteria for common cements. London, UK 
[26] British Standards Institute (2015) BS 8500: Complementary British standard to BS EN 206. London, UK

[27] De Carlo F, Xiao X, Tieman B (2006) X-ray tomography system, automation, and remote access at beamline 2-BM of the Advanced Photon Source. SPIE Opt Photon 6318:63180K. https://doi.org/10.1117/12.681037

[28] Gursoy D, De Carlo F, Xiao X, Jacobsen C (2014) TomoPy: a framework for the analysis of synchrotron tomographic data. J Synchrotron Radiat 21:1188-1193. https://doi.org/10. 1107/S1600577514013939

[29] Münch B, Trtik P, Marone F, Stampanoni M (2009) Stripe and ring artifact removal with combined wavelet: Fourier filtering. Opt Express 17:8567-8591. https://doi.org/10.136 4/OE.17.008567

[30] Paganin D, Mayo SC, Gureyev TE, Miller PR, Wilkins SW (2002) Simultaneous phase and amplitude extraction from a single defocused image of a homogeneous object. J Microsc 206:33-40. https://doi.org/10.1046/j.1365-2818.2002.01010 .x

[31] Dowd B, Campbell G, Marr R, Nagarkar V, Tipnis S, Axe L, Siddons D (1999) Developments in synchrotron X-ray computed microtomography at the National Synchrotron Light Source. SPIE's Int Sym Opt Sci Eng Instrum. https://d oi.org/10.1117/12.363725

[32] Deboodt T, Wildenschild D, Ideker JH, Isgor OB (2021) Comparison of thresholding techniques for quantifying portland cement hydrates using synchrotron microtomography. Constr Build Mater 266:121109. https://doi.org/10.101 6/j.conbuildmat.2020.121109

[33] Scrivener KL (2004) Backscattered electron imaging of cementitious microstructures: understanding and quantification. Cem Concr Compos 26:935-945. https://doi.org/10.10 16/j.cemconcomp.2004.02.029

[34] Schindelin J, Arganda-Carreras I, Frise E, Kaynig V, Longair M, Pietzsch T, Preibisch S, Rueden C, Saalfeld S, Schmid B (2012) Fiji: an open-source platform for biological-image analysis. Nat Methods 9:676-682. https://doi.org/10.1038/ nmeth.2019

[35] Schmid B, Schindelin J, Cardona A, Longair M, Heisenberg M (2010) A high-level 3D visualization API for Java and ImageJ. BMC Bioinform 11:274. https://doi.org/10.1186/14 71-2105-11-274

[36] Fan M, Chen Y, Wan K (2021) Representative elementary volume analysis of hardened cement paste during hydration using X-ray computed tomography. Constr Build Mater 277:122268. https://doi.org/10.1016/j.conbuildmat.2021. 122268

[37] Ghanbarian B, Hunt AG, Ewing RP, Sahimi M (2013) Tortuosity in porous media: a critical review. Soil Sci Soc Am J 77:1461-1477. https://doi.org/10.2136/sssaj2012.0435
[38] Aït-Mokhtar A, Amiri O, Dumargue P, Sammartino S (2002) A new model to calculate water permeability of cementbased materials from MIP results. Adv Cem Res 14:43-49. h ttps://doi.org/10.1680/adcr.2002.14.2.43

[39] Debnath B, Sarkar PP (2019) Permeability prediction and pore structure feature of pervious concrete using brick as aggregate. Constr Build Mater 213:643-651. https://doi.org/ 10.1016/j.conbuildmat.2019.04.099

[40] Guo Y, Zhang T, Du J, Wang C, Wei J, Yu Q (2021) Evaluating the chloride diffusion coefficient of cement mortars based on the tortuosity of pore structurally-designed cement pastes. Microporous Microporous Mater 317:111018. http s://doi.org/10.1016/j.micromeso.2021.111018

[41] Tranter TG, Kok MDR, Lam M, Gostick JT (2019) pytrax: a simple and efficient random walk implementation for calculating the directional tortuosity of images. SoftwareX 10:100277. https://doi.org/10.1016/j.softx.2019.100277

[42] Provis JL, Myers RJ, White CE, Rose V, van Deventer JSJ (2012) X-ray microtomography shows pore structure and tortuosity in alkali-activated binders. Cem Concr Res 42:855-864. https://doi.org/10.1016/j.cemconres.2012.03. 004

[43] Promentilla MAB, Sugiyama T, Hitomi T, Takeda N (2009) Quantification of tortuosity in hardened cement pastes using synchrotron-based X-ray computed microtomography. Cem Concr Res 39:548-557. https://doi.org/10.1016/j.cemconres. 2009.03.005

[44] Bogue RH (1929) Calculation of the compounds in Portland cement. Ind Eng Chem Anal Ed 1:192-197. https://doi.org/ $10.1021 / \mathrm{ac} 50068 \mathrm{a} 006$

[45] Lerch W (1946) The influence of gypsum on the hydration and properties of portland cement pastes. Proc Am Soc Test Mater 46:1252-1291

[46] Odler I, Wonnemann R (1983) Effect of alkalies on portland cement hydration II: alkalies present in form of sulphates. Cem Concr Res 13:771-777. https://doi.org/10.1016/00088846(83)90078-9

[47] Juilland P, Nicoleau L, Arvidson RS, Gallucci E (2017) Advances in dissolution understanding and their implications for cement hydration. RILEM Tech Lett 2:90-98. https://doi. org/10.21809/rilemtechlett.2017.47

[48] Birchall JD, Howard AJ, Double DD (1980) Some general considerations of a membrane/osmosis model for portland cement hydration. Cem Concr Res 10:145-155. https://doi. org/10.1016/0008-8846(80)90071-X

[49] Stein HN, Stevels JM (1964) Influence of silica on the hydration of $3 \mathrm{CaO}, \mathrm{SiO}_{2}$. J Appl Chem 14:338-346. http s://doi.org/10.1002/jctb.5010140805

[50] Brown PW, Pommersheim J, Frohnsdorff G (1985) A kinetic model for the hydration of tricalcium silicate. Cem Concr 
Res 15:35-41. https://doi.org/10.1016/0008-8846(85)900067

[51] Nicoleau L, Nonat A (2016) A new view on the kinetics of tricalcium silicate hydration. Cem Concr Res 86:1-11. http s://doi.org/10.1016/j.cemconres.2016.04.009

[52] Deboodt T, Wildenschild D, Ideker JH, Isgor OB (2019) Use of iodine for improving phase quantification using X-ray tomography. Cem Concr Res 116:102-112. https://doi.org/ 10.1016/j.cemconres.2018.11.004

[53] Juilland P, Gallucci E, Flatt R, Scrivener K (2010) Dissolution theory applied to the induction period in alite hydration. Cem Concr Res 40:831-844. https://doi.org/10.1016/ j.cemconres.2010.01.012

[54] Bellmann F, Sowoidnich T, Ludwig H-M, Damidot D (2015) Dissolution rates during the early hydration of tricalcium silicate. Cem Concr Res 72:108-116. https://doi.org/10.101 6/j.cemconres.2015.02.002
[55] Richardson IG (2008) The calcium silicate hydrates. Cem Concr Res 38:137-158. https://doi.org/10.1016/j.cemconres. 2007.11.005

[56] Bentz DP, Garboczi EJ (1991) Percolation of phases in a three-dimensional cement paste microstructural model. Cem Concr Res 21:325-344. https://doi.org/10.1016/0008-8846( 91)90014-9

[57] Gallucci E, Mathur P, Scrivener K (2010) Microstructural development of early age hydration shells around cement grains. Cem Concr Res 40:4-13. https://doi.org/10.1016/j.ce mconres.2009.09.015

Publisher's Note Springer Nature remains neutral with regard to jurisdictional claims in published maps and institutional affiliations. 